\title{
Constructing an Online MCAT Preparation Program as an Alternative to On-Site Preparation for Medical School
}

\author{
Berengaria Navarre ${ }^{1}$, Norma A. Perez ${ }^{1,2}$ \& Sarah Toombs Smith ${ }^{2,3}$ \\ ${ }^{1}$ Hispanic Center of Excelence, University of Texas Medical Branch, Galveston, TX, USA \\ ${ }^{2}$ Department of Internal Medicine, University of Texas Medical Branch, Galveston, TX, USA \\ ${ }^{3}$ Sealy Center on Aging, University of Texas Medical Branch, Galveston, TX, USA \\ Correspondence: Sarah Toombs Smith, Sealy Center on Aging, University of Texas Medical Branch, Galveston, \\ TX, 77555-0177, USA. Tel: 1-409-266-9655. E-mail: stoombs@utmb.edu
}

Received: May 26, 2017

doi:10.5539/jel.v6n4p191
Accepted: June 27, 2017

Online Published: July 5, 2017

URL: http://doi.org/10.5539/jel.v6n4p191

\begin{abstract}
Based on a successful five-week summer program, we constructed an online alternative to prepare Hispanic students to take the Medical College Admission Test (MCAT). We used input from student premed advisors, students, a faculty mentor, a Verbal Reasoning coach, and the program administrator. Online activities were provided to support the student commitment of 10-12 hours per week for 12 weeks. We included didactic material, an online community, individual coaching, daily announcements, and structured activities to maintain student interest throughout the 12 -week program. This case study may provide guidelines on the elements necessary to a successful online program.
\end{abstract}

Keywords: online learning, Medical College Admission Test, MCAT, diversity, Hispanic students, mentoring

\section{Introduction}

\subsection{Programs to Prepare Underrepresented Students for Success in Medical School}

For many years, United States federal and state funds have supported premedical enrichment programs to encourage minority and disadvantaged students to pursue medical careers. Traditional programs have embraced bringing the students to medical school campuses and exposing them to the medical school experience which includes, but is not limited to, meeting the faculty, experiencing medical courses, shadowing of a diverse realm of specialties, and admission advice (Murray-Garcia \& Garcia, 2002; Parrish, Daniels, Hester, \& Colenda, 2008; McDougle, Way, \& Yash, 2008; Blakely \& Broussard, 2003; Giordani et al., 2001; Crump, Byrne, \& Joshua, 1999; McGlinn, Jackson, \& Bardo, 1999; Thomson, Ferry, King, Martinez-Wedig, \& Michael, 2003; Lieberman, et al., 2010). This may also be accompanied by intense academic preparation for the Medical College Admissions Test (MCAT), a standardized test of academic preparation for medical school in the United States (McGaghie, 2002). Until 2012, the MCAT consisted of three multiple-choice sections in the Biological Sciences, Physical Sciences and Verbal Reasoning (now called Biological and Biochemical Foundations of Living Systems, Chemical and Physical Foundations of Biological Systems, and Critical Analysis and Reasoning Skills [CARS]) and an essay writing component, administered during one four-hour period. The essay was eliminated in preparation for major changes that included the addition of a section on Behavioral Health (Psychological, Social and Biological Foundations of Behavior) and a greater emphasis throughout on critical thinking skills.

\subsection{Preparing Students with a Five-Week Summer Preparation Program}

From 2011 to 2013, we conducted an on-site summer five-week MCAT preparation program for 50 undergraduate rising juniors and seniors. The students came from across Texas and were predominantly Hispanic. We modelled the program on existing undergraduate summer programs in our institution, but designed our courses from the ground up. We contracted faculty for the science courses (biology, chemistry, organic chemistry, and physics). We added a biostatistics course to introduce the concept of public health, article dissection to improve analytical capabilities, CPR certification, personal health and wellness, a library workshop focused on finding and validating scientific/medical information online, one-on-one mentoring sessions for rising seniors, and shadowing opportunities across disciplines and in our medical student run clinic. We recruited a senior 
science editor to create the Verbal Reasoning course, teach learning skills and hold personal statement workshops.

\subsection{Constructing an Online Program}

Despite our best efforts, students continued to be underprepared for the MCAT, the major roadblock to their entrance into medical school. We sought to devise a method to best prepare and motivate students to pass the MCAT, focusing on what could be accomplished in an online environment, constructed with limited resources, and provided asynchronously so that students could work the program into their schedule. Within this framework, engagement and self-motivation were intrinsic to the voluntary nature of the program and lack of non-completion repercussions. We first looked for similar programs at other institutions and found none reported in the literature. To construct our online program, we identified the problems to be addressed by this program, the key players and their roles in the development and administration of the program, and the resulting elements the program would need in order to be successful. This program may serve as a case study of how to construct an online program with students matriculated at other institutions.

\subsection{Literature Reivew}

By its nature, study for the MCAT is a voluntary undertaking resting on the day-to-day motivation of the individual to achieve and enter medical school. Additionally, our online program was free to students and conducted outside of their undergraduate institution courses. Only the student could choose to maintain momentum. Dennis, Bunkowski, and Eskey (2007) presented a classical literature review of motivation which offered strategies to sustain motivation with the idea of creating deeper learning experiences for the student. In particular, the authors proposed a campaign of directed actions with specific goals that would connect with today's students. Learners need to understand clearly what is expected of them and what actions demonstrate comprehension in order to motivate them. Learners must each be empowered with control of their learning (Dennis et al., 2007).

This motivation becomes even more important in terms of outcomes. Artino (2007) claimed a direct relationship between student choice of the online environment (choosing to participate in a course, having taken courses previously in an online environment, or intent to take further online courses) and student satisfaction, perceived learning, and task value. Perceived successful engagement in an online environment led to more successful engagement in the learning experience. While this study was limited in scope, the author concluded that a learner-reported positive online learning experience provided intrinsic motivation, potentially sustainable by further positive experiences. Positive engagement within the online classroom and program would motivate the student to more positive engagement.

Could the advisors/facilitators be the pivotal success factors? Woodthorpe, Shaw, Hauck, and Beaven (2009) concluded that tasks non-essential to grades were perceived as having minimal value, and teacher-guided motivation was crucial to sustaining participation and perceived value. Fritz (2011) also found that self-motivation is not always the answer and that instructor input was crucial to creating self-motivation. Instructor-initiated motivation, Fritz (2011) argued, could be positive and successful. In this study, the author found that underperforming students were accessing the content management system $39 \%$ less than more successful students.

\subsection{Research Design}

We concluded that student buy-in to a study plan through adoption of provided options, refinement, or joint creation would give ownership of the process to the student and create better engagement. The online classroom and engagement with advisors would be judgement free and each result would be a positive step along the individual's path. Clear expectations and mentorship would be key to maintaining student motivation and engagement.

\section{Method}

\subsection{Problems to be Addressed}

We used lessons learned from our on-site program to develop an online, asynchronous MCAT preparation program. Feedback from instructors (including basic science course grades, practice exams, and student engagement) from students (including course reviews and overall program reviews) and staff observations led us to conclude that a broader scope of engagement was needed to prepare these students. We observed that our students spent no more than three weeks preparing for the MCAT, not more than three to four hours each week, and were inconsistent from week to week. Our students also worked, were committed to extensive family 
activities, and dedicated time to multiple student organizations. Students also tended to use one review source, often outdated, or attempted to memorize text books. Very few sought resources online. Based on these observations, we concluded that students needed structure to study; a plan on what to study, how to study, how long to study, and why to study; and access to a mentor/advisor. Informal reviews of the literature and online resources such as WikiPremed and the Student Doctor Network indicated that three to four months of self-preparation were standard in order to obtain a competitive score on the MCAT (Student Doctor Network, 2017; Wetzel, 2017). Because of their disadvantaged status, we believed our students would require more time, daily supervision, and outside motivation. Realistically, asking students to commit to 10 to 12 hours a week was practical only as long as we structured a time-specific plan. We used Canvas Instructure to provide a platform to deliver the engagement, structure, time commitment, supervision, and motivation students needed (Table 1).

Table 1. Program Layout in Canvas (engagement, structure, time, supervision, motivation)

\begin{tabular}{|c|c|c|c|}
\hline Type & Description & Purpose & Maps to \\
\hline Daily Announcements & $\begin{array}{l}\text { Inspirations, links to resources, study skills, } \\
\text { important information on the program }\end{array}$ & $\begin{array}{l}\text { Provide motivation for students } \\
\text { to continue }\end{array}$ & Motivation \\
\hline Didactic Modules & $\begin{array}{l}\text { Weekly science assignments }+ \text { Verbal } \\
\text { Reasoning }\end{array}$ & $\begin{array}{l}\text { Provide intellectual content and } \\
\text { study strategies }\end{array}$ & $\begin{array}{l}\text { Engagement, Time, } \\
\text { Supervision }\end{array}$ \\
\hline Discussions & $\begin{array}{l}\text { Weekly topics were posed on Monday and } \\
\text { students encouraged to discuss them through } \\
\text { the end of the week }\end{array}$ & $\begin{array}{l}\text { Allow for student interaction } \\
\text { with peers to support and } \\
\text { encourage intellectual curiosity }\end{array}$ & \\
\hline People & Contact information provided & Peers to contact each other & Motivation \\
\hline Files & Readings, pdfs, etc. & Houses additional resources & Motivation \\
\hline Quizzes & $\begin{array}{l}\text { Exercises related to the topics of that week (see } \\
\text { Table 3) }\end{array}$ & $\begin{array}{l}\text { Provide both a means of } \\
\text { self-assessment and another } \\
\text { form of accountability }\end{array}$ & Supervision \\
\hline
\end{tabular}

\subsection{Key Players and Their Roles}

We identified five key players who would need to contribute to the program to make it successful: the campus premedical (pre-med) advisor, the student participants, the faculty advisor, the Verbal Reasoning coach, and the program administrator. The premed advisor would identify premed students whose grades were good, but who needed additional help in preparing for the MCAT. Students would agree to commit 10-12 hours a week to a rigorous 12-week program. The faculty advisor would commit time each week to an online synchronous hour for discussion and advice, as well as provide guidance to program attendees. The Verbal Reasoning coach would recreate instruction on Verbal Reasoning in the online environment and provide additional instruction in study habits, time management, and test preparation. The program administrator would gather all materials, devise a program, build the online environment, administer the program, and help students with administrative issues (i.e., how to $\log$ on, problems with connecting, etc.).

\subsection{Elements of the Program}

Our experience with an on-site summer program and knowledge of similar postbaccalaureate programs (Murray-Garcia \& Garcia, 2002; Parrish, Daniels, Hester, \& Colenda, 2008; McDougle, Way, \& Yash, 2008; Blakely \& Broussard, 2003; Giordani et al., 2001; Crump, Byrne, \& Joshua, 1999; McGlinn, Jackson, \& Bardo, 1999; Thomson, Ferry, King, Martinez-Wedig, \& Michael, 2003; Lieberman et al., 2010) indicated that students would need didactic materials, a path through the 12 weeks of the program, encouragement to continue, feedback on their progress, and a sense of community. 


\section{Results}

\subsection{Timeline of Events}

We developed the program over the fall of 2013. We constructed a 12-week online asynchronous program in Canvas using established best study practices, based on a review of commercial study programs, Wiki Premed, and the Student Doctor Network online materials (Student Doctor Network, 2017; Wetzel, 2017). Some of the material from the Student Doctor Network is now available in book form (Becker \& Burnett, 2010).

\subsection{Contributions of Program Partners}

\subsubsection{Pre-Med Advisors}

To build accountability into the system and strengthen ties with available resources at their home institutions, qualified candidates were required to apply through their pre-med advisor. Pre-med advisors served as recruiters and gatekeepers. Because some students are non-traditional, pre-med advisors also identified graduates who might be good candidates for medical school. We asked the advisors to supply an unofficial transcript and a short recommendation for each student. A review committee of medical school faculty (MDs and PhDs) assessed the records of each student and recommended those most likely to benefit from admittance into the program.

\subsubsection{Students}

Forty-nine unique students enrolled in the MCAT Online Program and 123 unique students attended the on-site program. Table 2 below provides the demographic characteristics and follow-up results for both groups. Demographically, the two groups were similar: slightly more female than male, mostly Hispanic and other minorities, and many reporting a language spoken at home other than English. For both cohorts, a large number could not be followed up. Of those reporting their career path, slightly more of the online students reported attending medical school (39\% versus $26 \%$ ) but both cohorts reported the same percentage (12\%) pursuing some a healthcare profession other than medical school.

Table 2. Demographic characteristics and outcomes for online program and summer attendees

\begin{tabular}{lcc}
\hline & Online Program attendees (n=49) & Summer attendees (n=123) \\
\hline Demographics & $19(39 \%)$ & $54(44 \%)$ \\
Gender (male, \%) & $44(90 \%)$ & $112(91 \%)$ \\
Race/Ethnicity (not non-Hispanic White, \%) & $33(67 \%)$ & $110(89 \%)$ \\
First Language not English (n, \%) & $19(39 \%)$ & $32(26 \%)$ \\
Outcomes & $6(12 \%)$ & $15(12 \%)$ \\
Attended medical school & 0 & $4(3 \%)$ \\
Other Health Care field & $24(49 \%)$ & $72(59 \%)$ \\
Other career path & & \\
Still in school/lost to follow up & & \\
\hline
\end{tabular}

Students in the online program were required to have a 3.5 overall Grade Point Average (GPA), a 3.6 science GPA, and to have completed the required science courses. Students invited into the program received intensive orientation the first week (Figure 1). They were introduced to the Canvas program site and given a tour of the different sections. They were instructed in how to join online discussions and shown where they could contact each other, the course administrator, or the faculty mentor. 


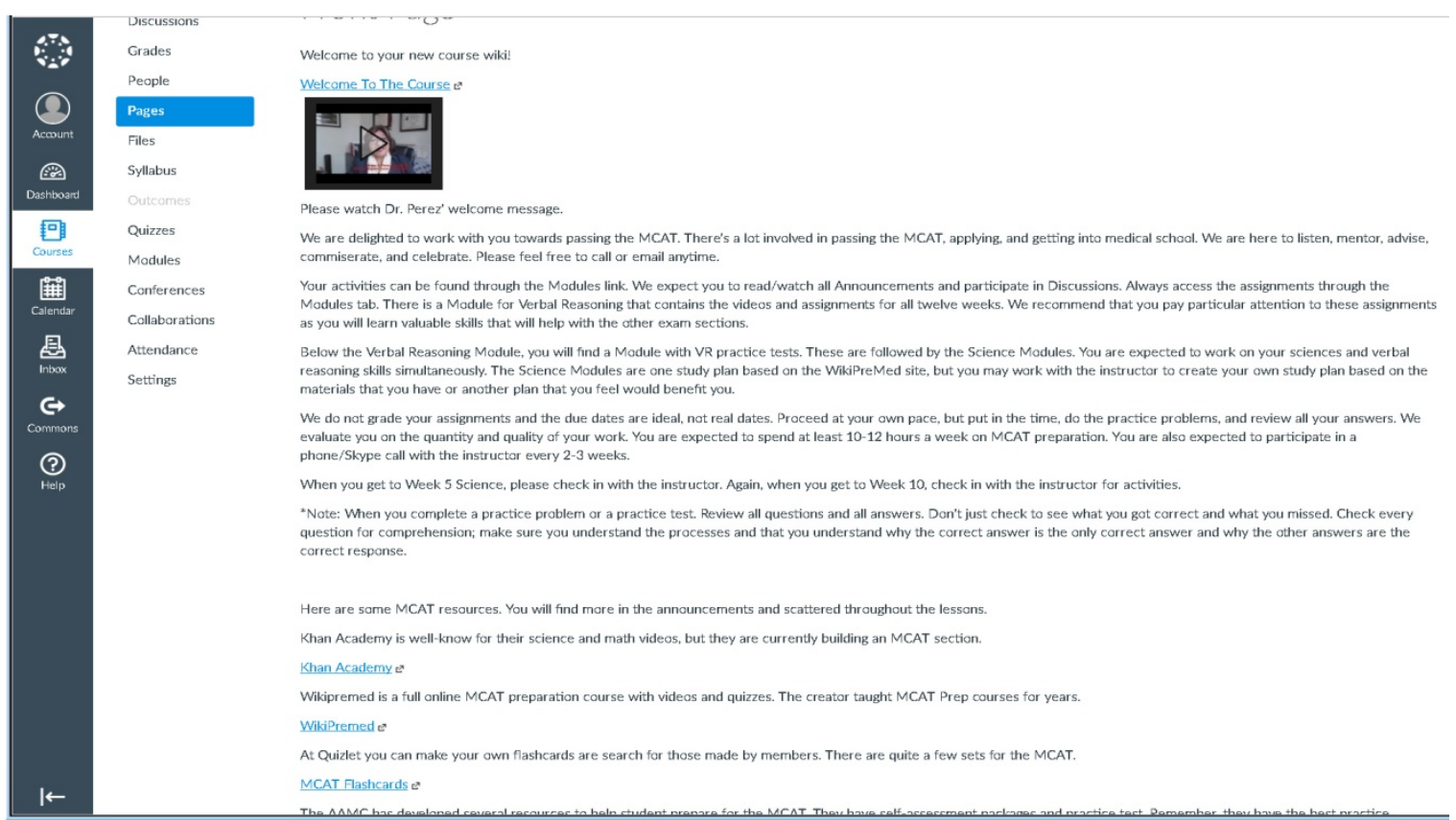

Figure 1. Screenshot of Canvas website for Online MCAT Preparation Program

Students were encouraged to keep up with the weekly timetable (Table 3) and to work in the Canvas classroom at least four days of the week. They submitted assignments to demonstrate participation, but not for grading. They were responsible for reviewing each of their practice questions and ensuring that they understood why the correct answer was the only appropriate answer and why each of the other answers were incorrect. This process helped show the students how to take responsibility for their own learning.

Table 3. Sample weekly schedule of activities

\begin{tabular}{|c|c|c|c|}
\hline Week 3 & $\begin{array}{l}\text { Wikipremed (Science) } \\
\text { Plan }\end{array}$ & Activities & Deliverables \\
\hline & Assignment 1 & $\begin{array}{l}\text { Work, Energy, and Power (videos, reading, vocabulary } \\
\text { review, crossword puzzle, practice questions, review } \\
\text { questions and make notes, flashcards) } \\
\text { Work, Energy, and Power Quiz }\end{array}$ & $\begin{array}{l}\text { Answers to crossword, practice } \\
\text { questions, notes, and quiz }\end{array}$ \\
\hline & Assignment 2 & $\begin{array}{l}\text { Discussion (Provide response to discussion question, } \\
\text { respond to } 2 \text { classmates) }\end{array}$ & $\begin{array}{l}\text { Responses to discussion } \\
\text { questions }\end{array}$ \\
\hline & Assignment 3 & $\begin{array}{l}\text { Momentum and Impulse (videos, reading, vocabulary } \\
\text { review, crossword puzzle, practice questions, review } \\
\text { questions and make notes, flashcards) }\end{array}$ & $\begin{array}{l}\text { Answers to crossword, practice } \\
\text { questions, and notes }\end{array}$ \\
\hline & Review & $\begin{array}{l}\text { Review weeks } 2 \text { and } 3 \text { readings, conceptual vocabulary, } \\
\text { and physics subtopics outline }\end{array}$ & \\
\hline \multirow[t]{3}{*}{ Week 3} & Verbal Reasoning & & \\
\hline & Reading Plan & $\begin{array}{l}\text { Reading Plan: video on creating a reading plan for } \\
\text { humanities, social sciences, natural sciences, and } \\
\text { technology, creating reading lists, and sources of readings, } \\
\text { practice critical reading not skimming }\end{array}$ & Reading lists \\
\hline & Assignments & $\begin{array}{l}\text { Take Verbal Reasoning Practice 2, review answers and } \\
\text { note types of mistakes, record in spreadsheet, plan } \\
\text { readings }\end{array}$ & $\begin{array}{l}\text { Update spreadsheet with test } \\
\text { results and types of mistakes }\end{array}$ \\
\hline
\end{tabular}




\subsubsection{Faculty Advisor}

The faculty advisor recorded a "welcome" video for students to view during the orientation. The advisor also attended each weekly meeting (conducted in Canvas) during which topics related to the MCAT and medical school were discussed. The advisor provided guidance to program attendees via Skype, phone, and email.

\subsubsection{Verbal Reasoning Coach}

The Verbal Reasoning component was given its own 12-week module as this was another area in which our students needed more instruction because many spoke English as a second language and their science-based education provided limited opportunities to enhance their verbal reasoning skills. This section included videos, PowerPoint presentations, and forms for the students to document their progress. At the students' request, the instructor did a real-time sample test, talking through the questions while selecting answers; she then graded her responses and talked about why she missed some of the questions (e.g., confusing wording, trying to hurry, mental fatigue).

\subsubsection{Program Administrator}

The Program Administrator gathered materials, set up the online classroom, assembled and send out the daily announcements, set up online discussions, and provided a conduit for classroom activities.

\subsection{Structure}

In the online classroom, we laid out twelve weeks of modules focused on the science portion of the MCAT, primarily drawn from the structure provided by Wiki Premed and our own structure devised for the Verbal Reasoning section. For example, in Week 3, students studied the following for Chemistry: modern periodic properties, chemical bonding, intermolecular force, organic functional groups, stereochemistry, and molecular spectroscopy; for Physics, they studied nuclear physics and atomic theory; for Verbal Reasoning, they devised an outside reading plan to help them increase reading speed and sensitivity to context in interpreting texts. For the science topics, we chose Wiki Premed because it initially focuses on physics, which was a problem area for most of our students. In addition, Wiki Premed had videos, was free, and was readily available to all students. We asked students who followed these modules to obtain the ExamKrackers study guides to support the activities. Alongside the Wiki Premed activities, we added links to other lesson sites and academic resources.

\subsection{Other Online Resources}

Other sections of the Canvas course provided additional resources to reinforce retention and learning (Table 1). A daily announcement section was used to offer alternative three month study plans, general study tips and MCAT specific study tips, inspirational quotes and articles, tip of the day, topic specific resources, online MCAT resources, recommended apps, course announcements, video resources, life tips, and just for fun (Figure 2). The announcements were a daily reminder that real people were involved with the student's preparation and actively seeking to support their efforts. A people section housed contact information for students and faculty, but also allowed us to view student time in the classroom and progress in the activities. The file section housed reading materials, relevant pdfs, Excel sheets, and other uploaded materials. 


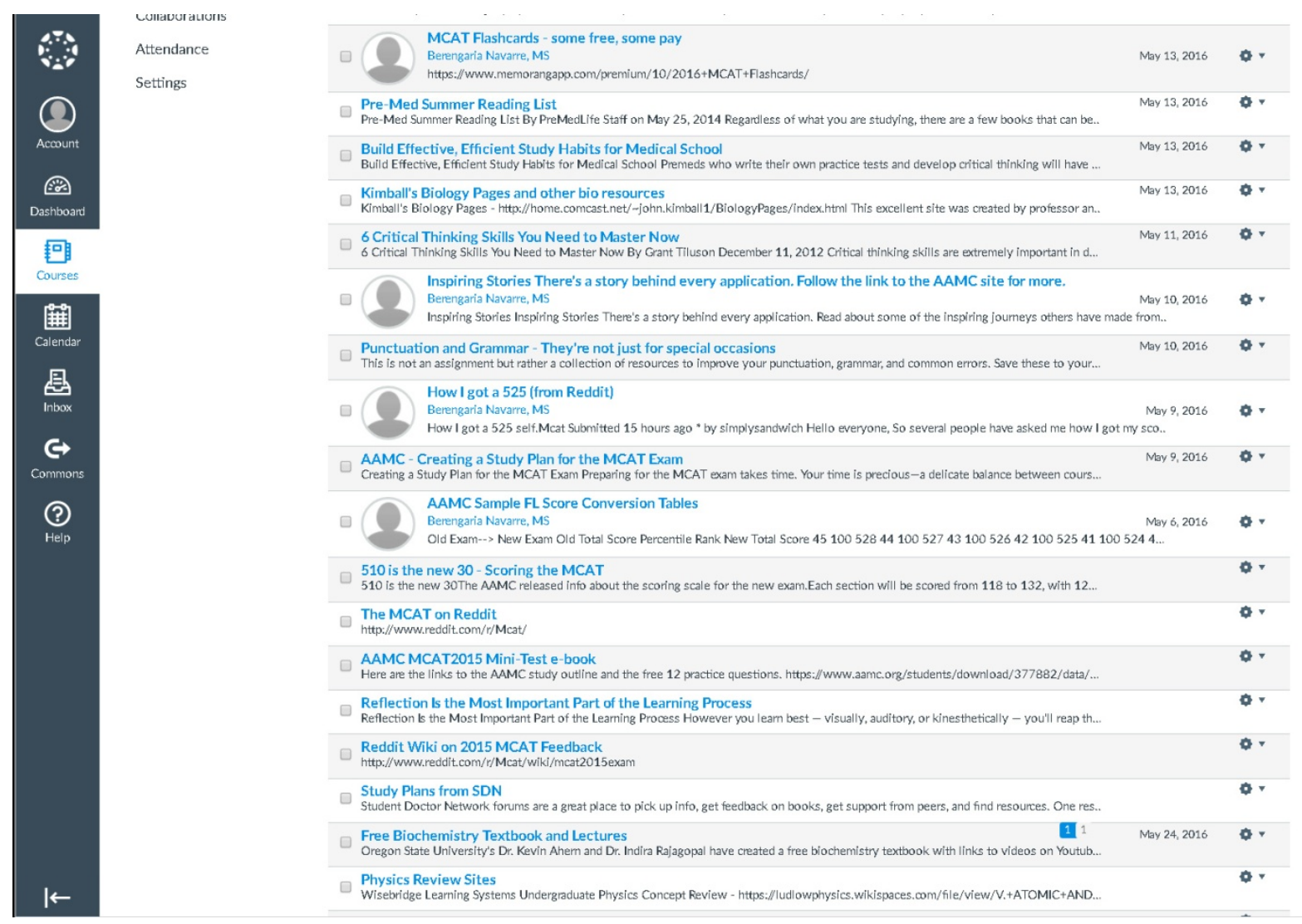

Figure 2. Screenshot of daily announcements

\subsection{Open Communication}

A key component in the design and implementation of the program was the mentorship and advisorship. Each student received a phone call to discuss the program before they were admitted and were required to participate in one-on-one phone calls at least every two weeks. Students who did not work within the online classroom in a given week were emailed and then called. Calls were framed as a positive way to get the student "back on track" as opposed to a punitive measure. We often reiterated that students could call our offices during office hours and we would arrange phone calls outside office hours. All student emails were answered within 24 hours. Students readily availed themselves of the opportunity to speak with us about the MCAT, study plans, medical school admissions, personal statements, personal and family issues that affected their studies, or simply to connect with someone that day in a judgement-free space.

\section{Discussion}

The MCAT is a valid prediction of success in medical school, particularly passing the US Medical Licensing Examination (USMLE) Step 1 test (Julian, 2005). Online materials for the science are readily available; by themselves, they will not assure success. Online students require engagement, structure, a time commitment, daily supervision, and outside motivation. In particular, satisfaction with an asynchronous online course and perceived learning have been linked to clear course design, interaction with instructors, and active discussion with other students in the course (Swan, 2001). Our program provided all of these, by gathering materials, developing new content, scheduled online discussions, and proving personal contact with both the program advisor and the program administrator.

Although our intent was to provide an alternative to on-site MCAT preparation, we quickly realized that this program needed an intensive time commitment in order to help students with their plan of study. Initially, students started out with the plan in our learning management system, Canvas. As the students progressed, we worked with them individually to access progress and to tailor the plan to meet their needs. We worked to eliminate weaknesses and to increase the number of practice questions done and reviewed. We helped them to 
decide how often they took practice tests and to interpret the results. We helped them decide test dates and when it was prudent to postpone. We also devoted many hours to reinforcing students' commitment to the program. All students required regular encouragement, support, and advice. When their efforts did not meet their expectations, they required intense mentoring.

The Verbal Reasoning portion of the test, now called Critical Analysis and Reasoning Skills (CARS), directly addresses the ability to apply critical thinking skills. Success on this section has been directly tied to student performance on the USMLE Step 1 test, administered after the first year of medical school and an important measure of retention (Julian, 2005). At the time this program was developed, no online sources provided guidance for this section. After the Program was administered, the Verbal Reasoning instruction was published in book format to benefit other students (Toombs Smith, 2014). Critical thinking skills have long been recognized as essential to student development into independent learners (Halpern, 1999). Khan Academy (2017) now devotes a section of its MCAT Preparation area to CARS.

Although its predictive value has been called into question (Donnon, Paolucci, \& Violato, 2007), the MCAT remains an important fixture (some would say a roadblock) of the path into medical school, Students prepare to take the MCAT in a variety of ways, from the most structured to the most disorganized. These methods include individual study, informal or formal groups, such as undergraduate premed groups (Rumala \& Cason, 2007), using study texts, online resources, or in formal classes such as those offered by The Princeton Review (2017) or Kaplan Test Prep (2017). Ranging from a few week to an entire summer, these programs can cost over $\$ 9,000$ for a six-week program (not including room and board). The usefulness of these professional preparations methods has recently been called into question (McGaghie, Downing, \& Kubilius, 2011).

Universities have increasingly turned to the online environment for some or all of their instruction, to reduce costs while maintaining quality (Twigg, 2003). For medical school, preparation may include an additional post-baccalaureate year to increase the likelihood of success (Lipscomb, Mavis, Fowler, Green, \& Brooks, 2009). Disadvantaged students continue to matriculate to and stay in medical school at rates below those of majority students (Sullivan \& Mittman, 2010; Odom, Roberts, Johnson, \& Cooper, 2007). Because their presence is important in the medical workforce (AAMC, 2017), efforts will continue to find ways to help such student succeed.

\section{Acknowledgments}

This work was supported in part by Health Resources and Services Administration (HRSA) grant D34HP-18956. The funder had no role in the preparation of this article, analysis or decision to publish. The authors thank the students and colleagues whose experience, insight, and wisdom helped shape the development of this program.

\section{References}

Artino, A. R. (2007). Online military training: Using a social cognitive view of motivation and self-regulation to understand students' satisfaction, perceived learning, and choice. Quarterly Review of Distance Education, 8(3), 191-202.

Association of American Medical Colleges (AAMC). (2017). At a Glance: Black and African American Physicians in the Workforce. AAMC News 21 Feb 2017: Diversity \& Inclusion. Retrieved April 25, 2017, from https://news.aamc.org/diversity/article/black-history-month-facts-and-figures/

Becker, C., \& Burnett, L. (2010). The Student Doctor Network's Medical School Admission Guide: From the SDN Experts, including Medical Students, Residents \& Physicians (2nd ed.). Minneapolis, MN: Two Harbors Press.

Blakely, A. W., \& Broussard, L. G. (2003). Blueprint for establishing an effective postbaccalaureate medical school pre-entry program for educationally disadvantaged students. Academic Medicine, 78(5), 437-447. https://doi.org/10.1097/00001888-200305000-00004

Crump, R., Byrne, M., \& Joshua, M. (1999). The University of Louisville Medical School's comprehensive programs to increase its percentage of underrepresented-minority students. Academic Medicine, 74(4), 315-317. https://doi.org/10.1097/00001888-199904000-00011

Dennis, K., Bunkowski, L., \& Eskey, M. (2007). The little engine that could-How to start the motor? Motivating the online student. InSight: A Collection of Faculty Scholarship, 237-249.

Donnon, T., Paolucci, E. O., \& Violato, C. (2007). The predictive validity of the MCAT for medical school performance and medical board licensing examinations: A meta-analysis of the published research. Academic Medicine, 82(1), 100-106. https://doi.org/10.1097/01.ACM.0000249878.25186.b7 
Fritz, J. (2011). Classroom walls that talk: Using online course activity data of successful students to raise self-awareness of underperforming peers. Internet and Higher Education, 14(2), 89-97. https://doi.org/10.1016/j.iheduc.2010.07.007

Giordani, B., Edwards, A. S., Segal, S. S., Gillum, L. H., Lindsay, A., \& Johnson, N. (2001). Effectiveness of a formal post-baccalaureate pre-medicine program for underrepresented minority students. Academic Medicine, 76(8), 844-848. https://doi.org/10.1097/00001888-200108000-00020

Halpern, D. F. (1999). Teaching for critical thinking: Helping college students develop the skills and dispositions of a critical thinker. New Directions for Teaching and Learning, 1999(80), 69-74. https://doi.org/10.1002/tl.8005

Julian, E. R. (2005). Validity of the Medical College Admission Test for predicting medical school performance. Academic Medicine, 80(10), 910-917. https://doi.org/10.1097/00001888-200510000-00010

Kaplan Test Prep. (2017). MCAT. Retrieved April 28, 2017, from https://www.kaptest.com/mcat

Khan Academy. (2017). Khan Academy MCAT Test Prep. Retrieved April 21, 2017, from https://www.khanacademy.org/test-prep/mcat

Lieberman, S. A., Ainsworth, M. A., Asimakis, G. K., Thomas, L., Cain, L. D., Mancuso, M. G., ... Frye, A. W. (2010). Effects of comprehensive educational reforms on academic success in a diverse student body. Medical Education, 44(12), 1232-1240. https://doi.org/10.1111/j.1365-2923.2010.03770.x

Lipscomb, W. D., Mavis, B., Fowler, L. V., Green, W. D., \& Brooks, G. L. (2009). The effectiveness of a postbaccalaureate program for students from disadvantaged backgrounds. Academic Medicine, 84(10), S42-S45. https://doi.org/10.1097/ACM.0b013e3181b37bd0

McGaghie, W. C., Downing, S. M., \& Kubilius, R. (2004). What is the impact of commercial test preparation courses on medical examination performance? Teaching and Learning in Medicine, 16(2), 202-211. https://doi.org/10.1207/s15328015tlm1602_14

McGaghie, W. C. (2002). Assessing readiness for medical education: Evolution of the medical college admission test. Jama, 288(9), 1085-1090. https://doi.org/10.1001/jama.288.9.1085

McGlinn, S., Jackson, E. W., \& Bardo, H. R. (1999). Postbaccalaureate Medical/Dental Education Preparatory Program (MEDPREP) at Southern Illinois University School of Medicine. Academic Medicine, 74(4), 380-382. https://doi.org/10.1097/00001888-199904000-00030

Murray-Garcia, J. L., \& Garcia, J. A. (2002). From enrichment to equity: Comments on diversifying the K-12 medical school pipeline. Journal of the National Medical Association, 94(8), 721.

Odom, K. L., Roberts, L. M., Johnson, R. L., \& Cooper, L. A. (2007). Exploring obstacles to and opportunities for professional success among ethnic minority medical students. Academic Medicine, 82(2), 146-153. https://doi.org/10.1097/ACM.0b013e31802d8f2c

Parrish, A. R., Daniels, D. E., Hester, R. K., \& Colenda, C. C. (2008). Addressing medical school diversity through an undergraduate partnership at Texas A\&M Health Science Center: A blueprint for success. Academic Medicine, 83(5), 512-515. https://doi.org/10.1097/ACM.0b013e31816be5cf

Rumala, B. B., \& Cason Jr, F. D. (2007). Recruitment of underrepresented minority students to medical school: Minority medical student organizations, an untapped resource. Journal of the National Medical Association, 99(9), 1000.

Student Doctor Network. (2017). Forums. Retrieved April 21, 2017, from https://forums.studentdoctor.net/

Sullivan, L. W., \& Mittman, I. S. (2010). The state of diversity in the health professions a century after Flexner. Academic Medicine, 85(2), 246-253. https://doi.org/10.1097/ACM.0b013e3181c88145

Swan, K. (2001). Virtual interaction: Design factors affecting student satisfaction and perceived learning in asynchronous online courses. Distance Education, 22(2), 306-331. https://doi.org/10.1080/0158791010220208

The Princeton Review. (2017). MCAT Prep. Retrieved April 28, 2017, from https://www.princetonreview.com/medical/mcat-test-prep

Thomson, W. A., Ferry, P. G., King, J. E., Martinez-Wedig, C., \& Michael, L. H. (2003). Increasing access to medical education for students from medically underserved communities: One program's success. Academic Medicine, 78(5), 454-459. https://doi.org/10.1097/00001888-200305000-00006 
Toombs Smith, S. (2014). 12 Week Plan for Verbal Reasoning Success. Seattle, WA: CreateSpace.

Twigg, C. A. (2003). Improving quality and reducing cost: Designs for effective learning. Change: The Magazine of Higher Learning, 35(4), 22-29. https://doi.org/10.1080/00091380309604107

Wetzel, J. (2017). The WikiPremed MCAT Course. Retrieved April 21, 2017, from http://www.wikipremed.com/

Woodthorpe, J., Shaw, J., Hauck, M., \& Beaven, T. (2009). What's in it for me? The stick and the carrot as tools for developing academic communities. Journal of Systemics, Cybernetics \& Informatics, 7(5), 22-24.

Yash, C. (2008). Effectiveness of a premedical postbaccalaureate program in improving medical college admission test scores of underrepresented minority and disadvantaged students. Journal of the National Medical Association, 100(9), 1021. https://doi.org/10.1016/S0027-9684(15)31438-3

\section{Copyrights}

Copyright for this article is retained by the author(s), with first publication rights granted to the journal.

This is an open-access article distributed under the terms and conditions of the Creative Commons Attribution license (http://creativecommons.org/licenses/by/4.0/). 